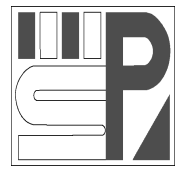

Science Press
Journal of Arid Land

2012, 4(4): 357-368

doi: 10.3724/SP.J.1227.2012.00357

jal.xjegi.com; www.chinasciencejournal.com

\title{
Vertical distribution of sand-dust aerosols and the relationships with atmospheric environment
}

\author{
Jie ZHANG $^{1 *}$, XingMing $\mathrm{LI}^{2}$ \\ ${ }^{1}$ Key Laboratory of Meteorological Disaster of Ministry of Education (KLME), Nanjing University of Information Science \& Technology, \\ Nanjing 210044, China; \\ ${ }^{2}$ Meteorological Institute of Shaanxi Province, Xi'an 710078, China
}

\begin{abstract}
The vertical distribution of aerosols in the troposphere is important for determining their effects on climate. The vertical distribution of aerosols under different atmospheric conditions in the free troposphere was directly observed using a surface micro-pulse LIDAR (MPL) and a TP/WVP-3000 microwave radiometer at the Semi-Arid Climate \& Environment Observatory of Lanzhou University (SACOL, $35.95^{\circ} \mathrm{N}, 104.10^{\circ} \mathrm{E}$ ) in the western Loess Plateau, China, in the spring of 2008. The results showed two possible transportation paths of a sandstorm from May 1 to May 4 in 2008. In one path, sand-dust aerosols were transported toward the east from the Taklimakan Desert to the Badain Jaran Desert and the Tengger Desert by a westerly wind and then toward the southeast to Jingtai and Lanzhou. A weak aerosol index (AI) indicated another possible transport path toward the east from the Taklimakan Desert to the Qaidam Basin and through the Tibetan Plateau eastward to SACOL. The aerosol profile of sandstorm processes over the SACOL area displayed three patterns: a single peak distribution under stable atmospheric conditions, indicating urban aerosol distribution; an exponential decrease under unstable atmospheric conditions in the presence of a sandstorm; and a slight change in the mixed layer during the first and last stages of the sandstorm, indicative of thorough mixing during lifting and deposition stages. Analyses of the aerosol layer height (ALH) showed that there are two types of ALH diurnal variation. The ALH during the first sandstorm stage was complex and disordered, and affected by atmospheric circulation. While the ALH had obvious diurnal variation in the other stage, the ALH and aerosol extinction coefficient (AEC) had a single peak, and was higher in the afternoon and lower in the morning. In the second case the ALH was in agreement with the atmospheric boundary layer height $(\mathrm{BLH})$ variation. As a result of the development of the atmospheric boundary layer (ABL) during day and maintenance at night, ALH during sandstorm-free days showed obvious diurnal variations. Multiple vertical distribution patterns of sand-dust aerosols will result in different climate effects; therefore, the vertical distribution patterns can be used to parameterize climate and aerosol models.
\end{abstract}

Keywords: aerosol profile; aerosol layer height; atmospheric boundary layer; atmospheric conditions; distribution pattern

Sandstorm is a meteorological phenomenon that frequently occurs in Asia. Studies have shown that sand-dust aerosols originate in the Taklimakan Desert and other deserts in northern and northwestern China. Sand-dust aerosols are frequently present in the troposphere and are transported in the atmosphere to eastern China, Korea, Japan, the Pacific Ocean, and North America through atmospheric circulation (Arimoto et al., 1996; Takemura et al., 2002; Uematsu et al., 2002; Iwasaka, 2003; Zhang et al., 2005; Huang et al., 2008a; Liu et al., 2008). Aerosols in the atmosphere produce radiative forcing (Derekand Malm, 2001; Nakajima et al., 2003; Won et al., 2004), which can result in atmospheric cooling from scattering of shortwave radiation or heating from absorption and emission of longwave radiation (Kim et al., 2004). These aerosols also exhibit complex chemical and optical properties as a result of contamination by other 
types of aerosols during the transportation process (Campbell et al., 2002; Anderson et al., 2003; Clarke et al., 2004; Huang et al., 2006b; Forster et al., 2007). Therefore, sand-dust aerosols in the troposphere have important extinction effects on the surface climate (Claquin et al., 1998; Pace et al., 2006), directly, by affecting the surface infrared radiation balance, and indirectly, by affecting the structures and properties of clouds (Levin et al., 1996; Shine et al., 1999; Yogesh et al., 2000; Day et al., 2001; Gille et al., 2003).

Understanding the vertical distribution of aerosols in the troposphere is important for determining their effects on the climate. Liao and Seinfeld (1998) demonstrated that net (shortwave and longwave) radiative forcing at the top of the atmosphere (TOA) under clear skies is sensitive to the vertical distribution of sand-dust aerosols. Meloni et al. (2005) found that the intensity of shortwave radiative forcing at the TOA is strongly dependent on the vertical distribution of aerosols. Kim et al. (2004) demonstrated that the distribution of water vapor in Asian sand-dust layers can increase the heating rate of net radiation, and that the change of water vapor is related to the vertical distribution of the heating rate. Therefore, the vertical distribution of sand-dust aerosols is a key parameter in the objective evaluation of radiance forcing ( $\mathrm{Li}$ et al., 2005; Kinne et al., 2006; Zhu et al., 2007). Moreover, understanding the dust-absorption properties in different regions will help to improve the parameterization of aerosol vertical distribution and eventually provide background field data for aerosol models, climate models (Kinne et al., 2006), and satellite-based remote-sensing algorithms (Levy et al., 2007; Zhang and Zhang, 2008). Current observation and modeling studies have shown that aerosols that originate from anthropogenic and natural emissions can be transported over long distances (Zhou et al., 2000; Liu et al., 2007). The aerosol profile is complex due to the variety of aerosol properties and weather conditions. Most aerosols are distributed within the boundary layer. However, aerosols from the Qinghai-Tibetan Plateau can be transferred to the free atmosphere when they are transported by relatively strong winds (Han et al., 2005); stratospheric aerosols originating from the Plateau have been observed using the CALIPSO satellite (Pace et al., 2006). Sand-dust aerosols in arid deserts can be transferred to the free atmosphere by wind transportation, dry-heat convection (Li et al., 2007a), dust tornadoes (Li et al., 2007b; Han et al., 2008) and other means. Thus, the vertical distribution of aerosols is highly uncertain.

Micro-Pulse Lidar (MPL) has been widely used around the world to understand the vertical structure of sand-dust aerosols and their physical properties (He and Mao, 2004; Niranjan et al., 2007). In 2008, the Sino-US Joint Dust and Sand Trial utilized equipment such as laser radars (MPL-4) and microwave radiometers (Huang et al., 2008b) to collect data at the Semi-Arid Climate and Environment Observatory of Lanzhou University (SACOL). In the paper, we obtainned the aerosol extinction coefficient (AEC) based on MPL data, and analyzed the vertical distribution of the AEC over the SACOL study area. The results of the study will be useful for parameterization of aerosol distribution as well as improving climate and aerosol models.

\section{Study area and methods}

The purpose of the Sino-US Joint Trial was to understand the climatic impacts of aerosols (especially sand-dust aerosols) and the effects of sand-dust aerosols on cloud reflectivity and precipitation process in East Asia. SACOL, located on the Loess Plateau $\left(35.95^{\circ} \mathrm{N}, 104.10^{\circ} \mathrm{E}\right)$, was the main study site (Huang et al., 2006a). The mobile platform, SACOL's Mobile Facility (SMF), was placed in Jingtai $\left(37.57^{\circ} \mathrm{N}\right.$, $104.23^{\circ} \mathrm{E}$ ), and a set of atmospheric radiation measurement devices (SMART-COMMIT) were placed in Zhangye $\left(39.08^{\circ} \mathrm{N}, 100.27^{\circ} \mathrm{E}\right)$. These three stations were distributed from west to east (Fig. 1), forming a micro-pulse LIDAR network (MPLnet) (Welton et al., 2001). Because the western region of the study area adjoins the Taklimakan Desert, a major source of sand-dust aerosols, and its northern edge is adjacent to the Tengger Desert and the Badain Jaran Desert, sandstorms at SACOL arise from these outer origins, and the local source of aerosols is from urban land. 


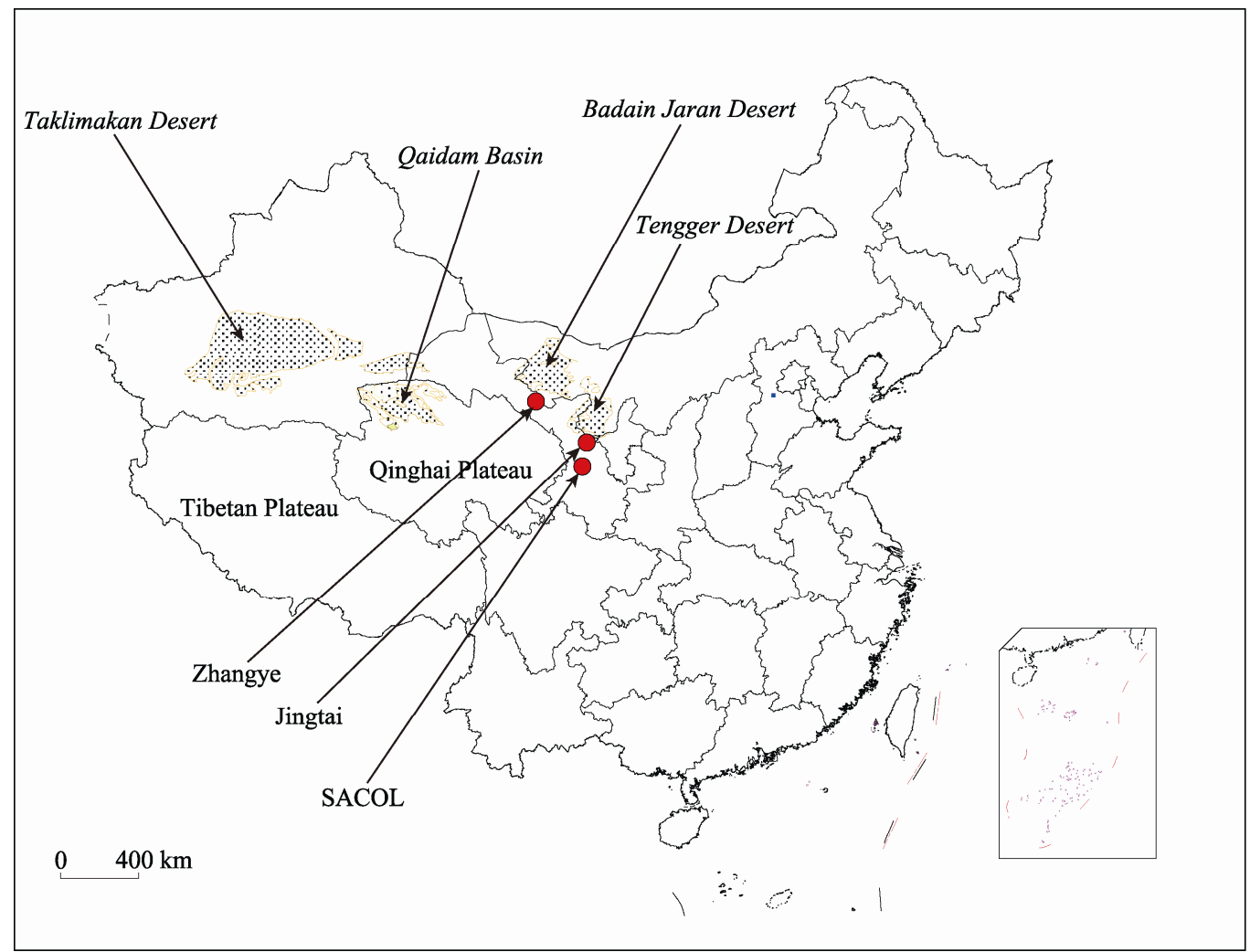

Fig. 1 Network of observation stations (SACOL, Jingtai, and Zhangye) and adjacent landform units

The MPL system employs an optical transceiver that acts as both a transmitter and a receiver (telescope), and consists of a pulsating Nd:YLF laser that operates at $527 \mathrm{~nm}$, an avalanche photo diode (APD) photon-counting detector, a signal-processing unit, and a data processor. The laser pulse duration was $100 \mathrm{~ns}$, yielding a vertical resolution of $75 \mathrm{~m}$. The range-corrected, normalized LIDAR return signal for one transmitted laser pulse is a combination of the backscattering energy from Rayleigh and aerosol components. Because MPL is sensitive to light noise, the instrument was protected from sunshine when the sky was clear. MPL has a small field of reception, which reduces the complexity of multi-scattering effects and the impacts of noise from sunlight (He et al., 2004). The data used in the study were obtained from the website http://climate.lzu.edu.cn. The accuracy of the laser radar at the observation stations was tested by comparing the aerosol optical thickness obtained using the laser radar to that of the sun photometer. Cloudy profiles were screened by a simple cloud-aerosol dis- crimination method. Backscattered intensities from clouds are generally stronger than those of aerosols, and this characteristic can be used to separate clouds from aerosols. Therefore, cloudy profiles were screened for backscattered intensities greater than 2, and the screened values were filled with linearly fit values. The fitted values were interpolated using data obtained from above and below the cloud layer.

A microwave radiometer (TP/WVP-3000) was installed at SACOL to measure the atmospheric temperature and water vapor profile at altitudes less than $10 \mathrm{~km}$ above ground for the analysis of the atmospheric conditions and atmospheric boundary layer (ABL) movement. The instrument included 5 measurement channels with frequencies between 22 and 30 $\mathrm{GHz}$ and 7 channels with frequencies between 51 and $59 \mathrm{GHz}$. A microwave radiometer with an infrared thermometer can provide low-resolution liquid water profiles and cloud base temperatures. Temperature was used for potential temperature (PT). The pressure values were calculated by barometric height formula. The 
top layer of the inversion PT with strength greater than $0.4^{\circ} \mathrm{C} / 100 \mathrm{~m}$ was defined as the boundary of the stable boundary layer (SBL). The height between this layer and the ground was determined to be the height of the SBL or boundary layer height (BLH) (Zhang and Wang, 2009). NCEP reanalysis data omega and wind vector at $700 \mathrm{hPa}$ were collected around the SACOL weather station for analyzing meteorological conditions during aerosol transportation. During the observation period in the spring of 2008, a strong sandstorm and drifting dust occurred for 11 consecutive days from April 28 to May 8 .

The ozone monitoring instrument (OMI) is a contribution of the Netherlands's Agency for Aerospace Programs (NIVR) in collaboration with the Finnish Meteorological Institute (FMI) to the EOS Aura mission, which will continue the Total Ozone Mapping Spectrometer (TOMS) record for total ozone and other atmospheric parameters related to ozone chemistry and climate. The OMI is a nadir-scanning instrument that measures backscattered solar radiation over a 270-500 nm wavelength range with a spectral resolution of $0.42-0.63 \mathrm{~nm}$. Spectral features of the solar shortwave backscatter in the visible (350-500 nm) and ultraviolet (UV-1, 270-314 nm and UV-2, 306-380 $\mathrm{nm}$ ) regions were observed using OMI. The OMI has a large field of view with a swath of $2,600 \mathrm{~km}$, a spatial resolution of $13 \mathrm{~km} \times 24 \mathrm{~km}$ at the nadir and daily global coverage (Sokolik et al., 1996). Because sand-dust aerosols contain silicon, aluminum, iron, calcium, and magnesium compounds, they can absorb much shortwave radiation. Based on this principle, Torres et al. (2005) produced an aerosol index (AI) using OMI and widely applied OMI to study sand-dust aerosols. In this study, AI was used to qualitatively describe the intensity of sand-dust aerosol particles and their transportation paths. The aerosol optical thickness $(\tau)$ was calculated based on the aerosol backscatter in the MPL:

$$
\tau=\int_{z_{1}}^{z_{2}} \sigma_{a}(z) d z .
$$

Where, $\sigma_{a}$ is the aerosol extinction coefficient. This coefficient can be obtained from the calculated backscattering strength according to Fernald (1984):

$$
\begin{aligned}
\sigma_{a}(z)= & -\frac{S_{a}}{S_{m}} \sigma_{m}(z)+ \\
& X(z) \exp \left[2\left(\frac{S_{a}}{S_{m}}-1\right) \int_{z}^{z_{0}} \sigma_{m}(z) d z\right] / \\
& \left\{X\left(z_{0}\right) /\left[\sigma_{a}\left(z_{0}\right)+\frac{S_{a}}{S_{m}} \sigma_{m}\left(z_{0}\right)\right]-\right. \\
& \left.2 \int_{z}^{z_{0}} X(z) \exp \left[2\left(\frac{S_{a}}{S_{m}}-1\right) \int_{z}^{z_{0}} \sigma_{m}(z) d z\right] d z\right\} .
\end{aligned}
$$

Where, $X(z)$ is the normalized signal; $z_{0}$ is the altitude of the radar; $z$ is the distance from the radar to the particle; $\sigma_{m}$ is the extinction coefficient (EC) of regionnal atmospheric molecules, obtained from the vertical structure of the atmospheric molecule density calculated by the U.S. standard atmospheric model and the Mie scattering theory $\left(S_{a}=\sigma_{a} / \beta_{a}\right)$ and $\sigma_{m}$ is between 20 and 70; $\beta_{a}$ is the aerosol backscattering coefficient; $\sigma_{a}$ is the molecular EC; $S_{m}=\sigma_{m} / \beta_{m}=8 \pi / 3 ; \Delta \mathrm{z}$ is $0.075 \mathrm{~km}$ and the difference between height $z$ and height $z+1$; and $\beta_{m}$ is the molecular backscattering coefficient.

\section{Results and discussion}

\subsection{Aerosol index distribution and atmospheric environment characteristics}

The aerosol index reflects the aerosol transportation path and intensity. Figure 2 shows the AI distribution and wind vector at $700 \mathrm{hPa}$ over SACOL and its surrounding areas from May 1 to May 4, 2008. The AI distribution was indicative of west-to-east aerosol transport from May 1 to May 4. The AI was continuously high in the Taklimakan Desert, and displayed many local characteristics. In addition to the Taklimakan Desert, an AI center was observed in Zhangye, Badain Jaran Desert, and Tengger Desert, and weak AI was detected over the SACOL station on May 1, indicating that the SACOL would be influenced by aerosols soon. Moreover, the obvious westerly wind at a level of $700 \mathrm{hPa}$ is indicative of a west-to-east aerosol transportation path. From the AI data of four days, it can be seen that there are weak aerosols over Qaidam Basin in the northern Tibetan Plateau, and another AI appeared in the Qinghai Plateau on May 3, from which it can be inferred that there is a trend of aerosol transport from the Taklimakan Desert toward the east th- 
rough the Qaidam Basin, or that the Qinghai Plateau and Qaidam Basin are possible sand aerosol sources due to surface desertification. In addition, in accordance with the terrain conditions of the Tibetan Plateau and Qilian Mountains, weak aerosols over the Tibetan Plateau, which lies to the immediate south of Qilian Mountains, will be affected by the westerly flow past the mountain body; therefore, an aerosol path in the northern Tibetan Plateau is possible. Four days of wind vector's direction at 700 $\mathrm{hPa}$ is not enough for firm conclusions regarding sand-dust aerosol path, however it can be demonstrated that southwest winds transport sand-dust aerosols from the Qinghai Plateau. The average altitude of the northern Tibetan Plateau is about 3,000 $\mathrm{m}$, therefore, wind vector at $700 \mathrm{hPa}$ can show surface wind direction with local characteristics, but cannot reflect air movement and aerosol transportation over Tibetan Plateau. An aerosol transport path through the Tibetan Plateau is a possibility, however it requires further tests. Figure 2 shows two paths of sand-dust aerosol transportation to the SACOL. It follows that the aerosols may originate upwind; additionally, local aerosols from urban land area unavoidably exist.

The transportation and lifting of aerosols is affected by atmospheric circulation. The omega from NCAR/ NCEP reanalysis reflects the characteristics of vertical air movement. The positive omega indicates descending movement and favors aerosol depositions. In contrast, a negative omega indicates ascending movement and favors aerosol transportation and lifting. Omega at $700 \mathrm{hPa}$ was used in the study because the sand-dust aerosol layer was observed at this height. (a) 01 May, 2008

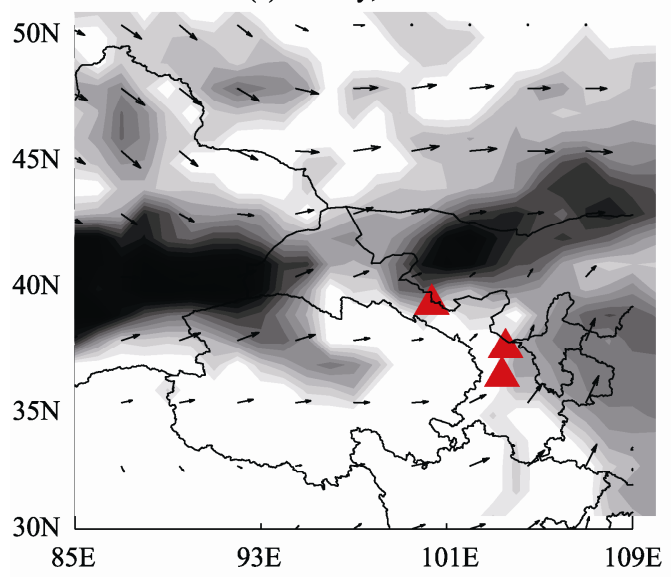

(c) 03 May, 2008

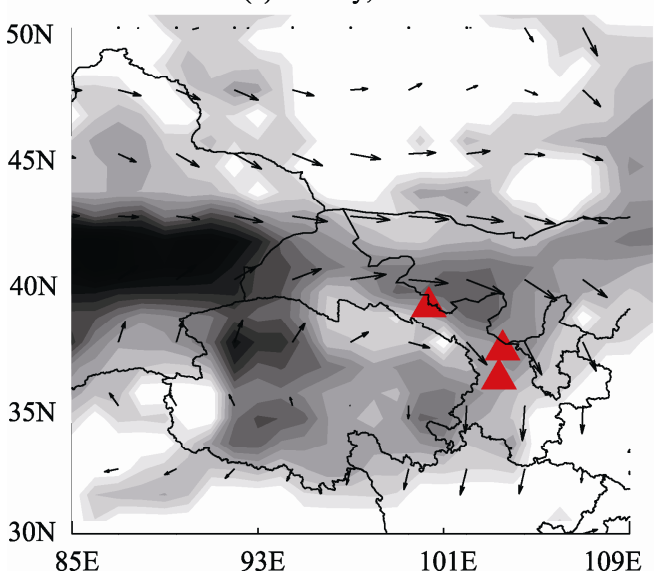

(b) 02 May, 2008

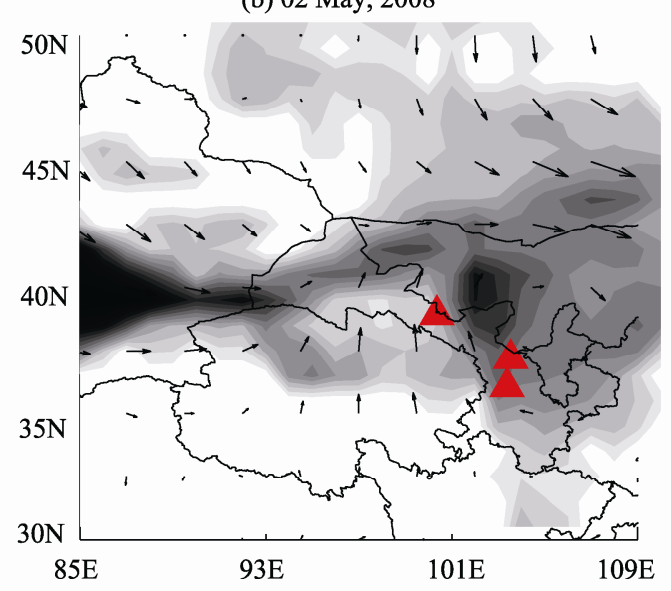

(d) 04 May, 2008

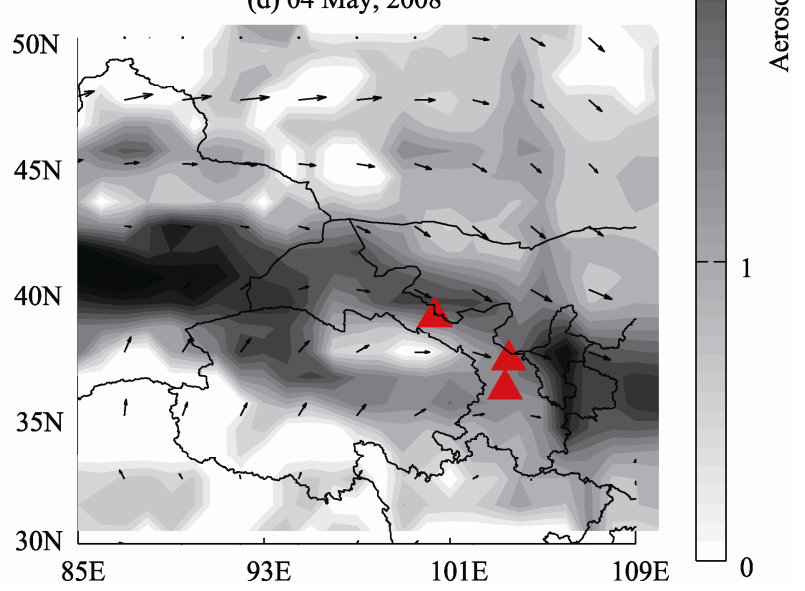

Fig. 2 The UV Al (shadow) calculated from OMI satellite and wind field at $700 \mathrm{hPa}$ (black arrows) at 14:00 LST, as obtained from the NCEP reanalysis data over northwestern China. The curves in the figures indicate provincial boundaries. 
As shown in Fig. 3, negative omegas were observed from 14:00 on May 1 to 8:00 on May 3 (Figs. 3a, e, i). The negative omega center was located in the Taklimakan Desert, and the movement was observed toward the east, indicating an ascending movement and lifting of eastward transported aerosols in the Taklimakan Desert. The negative omega center in the Badain Jaran and Tengger deserts was clearly moving from the northwest toward the SACOL on May 1 (Figs. 3c, d), indicating a strong ascending movement and lifting of aerosols in the Badain Jaran and Tengger deserts. Positive omegas over SACOL were observed at 8:00 on May 1 (Fig. 3b),

(a)

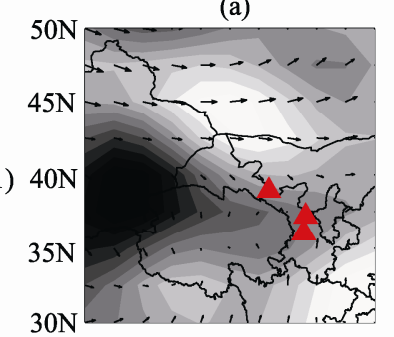

(e)

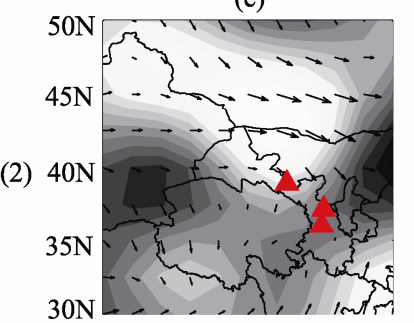

(i)

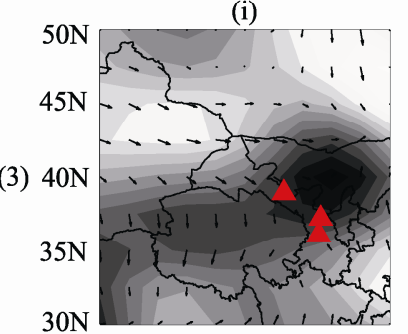

(m)

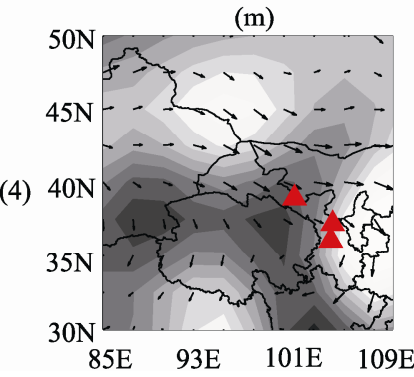

(b)

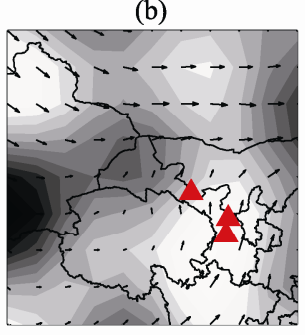

(f)

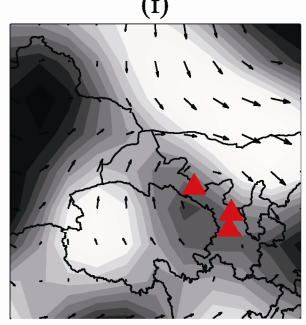

(j)

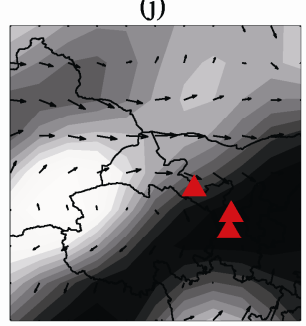

(n)

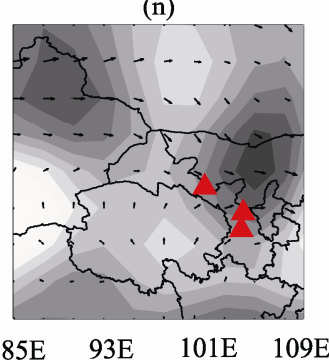

May 3, and May 4 (Figs. 3j, n), indicating a descending movement leading to aerosol sedimentation at SACOL. After 8:00 on May 4, negative omega at SACOL appeared, indicating that the atmosphere was unstable which favored aerosol lifting and transportation. Figures 2 and 3 illustrate that aerosols present over the Badain Jaran and Tengger deserts may be transported toward the SACOL, and sand-dust aerosols lifted from the Taklimakan Desert and the Qaidam Basin can be transported through the Tibetan Plateau toward the SACOL by a westerly wind. Passing sand-dust aerosols will influence the radiance at the SACOL.

(c)

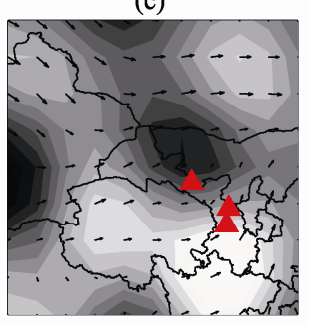

(g)

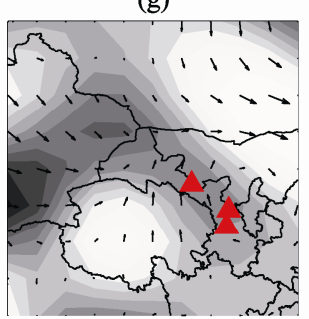

(k)

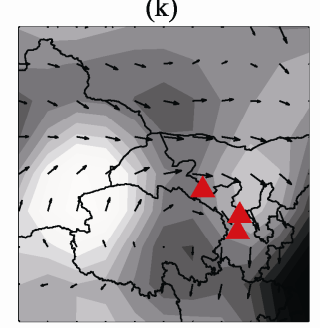

(o)

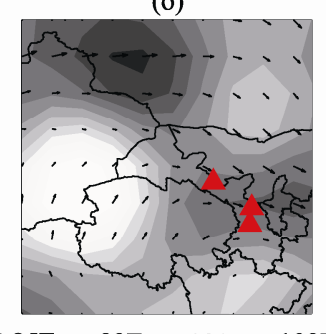

(d)

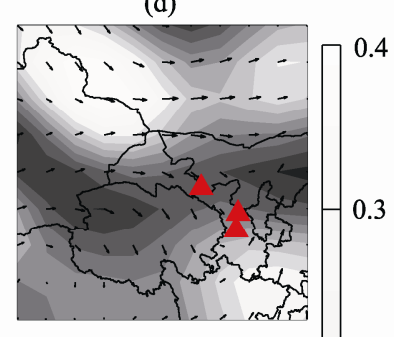

(h)

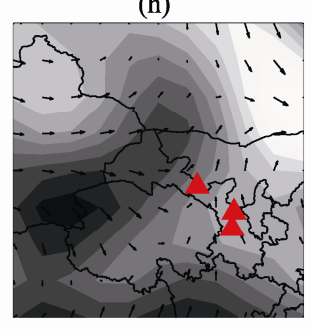

(1)

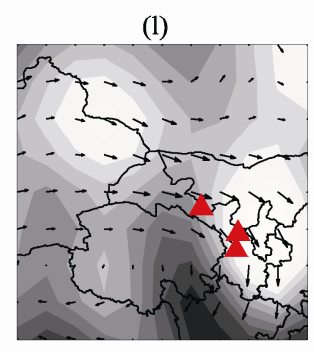

(p)

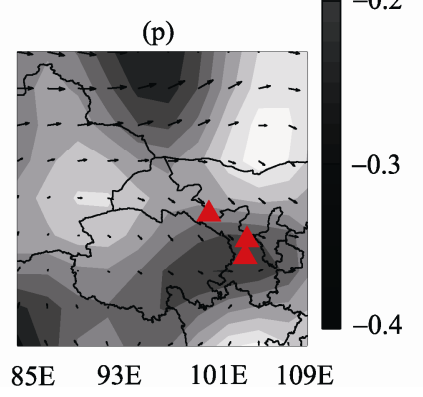

Fig. 3 The omega distributions (shadow) and wind fields at $700 \mathrm{hPa}$ (black arrows) over SACOL and the surrounding regions. (Rows (1) to (4) represent data obtained on May 1, May 2, May 3, and May 4, 2008, respectively. Columns (a) to (d) represent 2:00, 8:00, 14:00, and 20:00 LST, respectively. The curves in the figures indicate provincial boundaries.) 


\subsection{The temporal and vertical profile of sand-dust aerosol extinction coefficient}

During sandstorm periods, sand-dust aerosols are distributed as a function of the atmospheric conditions. The aerosol extinction coefficient demonstrates the extinction characteristics of aerosols: a large AEC indicates strong absorption and scattering or high aerosol content. When the difference between the AEC and air molecule EC is less than 0.02, the corresponding altitude is defined as the aerosol layer height (ALH). Figure 4 shows the vertical profile of AEC during a sandstorm period. The sandstorm lasted for three days, from 12:00 on May 1 to the afternoon on May 3. Strong aerosol extinction characteristics were observed from the ground surface to an altitude of 4 $\mathrm{km}$, and the aerosol content increased up to an altitude of $3.5 \mathrm{~km}$ after 12:00 on May 1. Large AEC values were observed after 12:00 on May 1 until May 3. After 20:00 on May 3, the AEC values began to decrease until 8:00 on May 4, when ALH was less than $0.4 \mathrm{~km}$. In the present study, the ALH was obvious, and was different on all three days. Specifically, it was higher on the first day, ranging from 2 to $5 \mathrm{~km}$, and high AEC was observed on the top of the aerosol layer after 16:00 LST. On May 2, the ALH decreased to a level below $2 \mathrm{~km}$ before 12:00 LST and then increased up to $2.5 \mathrm{~km}$ at noon. An aerosol layer was observed between 5 and $8 \mathrm{~km}$, indicating that aerosols were present in the free atmosphere as a result of convective lifting of aerosols from upstream sources by air movement (Huang, 2008b). On the third day, the height of the aerosol layer was within $2 \mathrm{~km}$ before 12:00 am, and a slight increase was observed at noon. The second peak was detected at $2 \mathrm{~km}$, indicating that the aerosol layer in the free atmosphere was derived from outer sources. The lower altitude peak was likely a response to local aerosols. These structures suggest the presence of strong, turbulent, mixed aerosols from near-surface levels or outer sources. On May 4, the AEC was less than $0.4 \mathrm{~km}^{-1}$, which is a normal value for sunny days, indicating that aerosols were distributed in response to the occurrence of a sandstorm-free day or local aerosols from the urban area. Because of ABL development during day and maintenance at night, the ALH on a sunny day was higher in the daytime and lower at night, and the peak ALH value was observed in the afternoon.

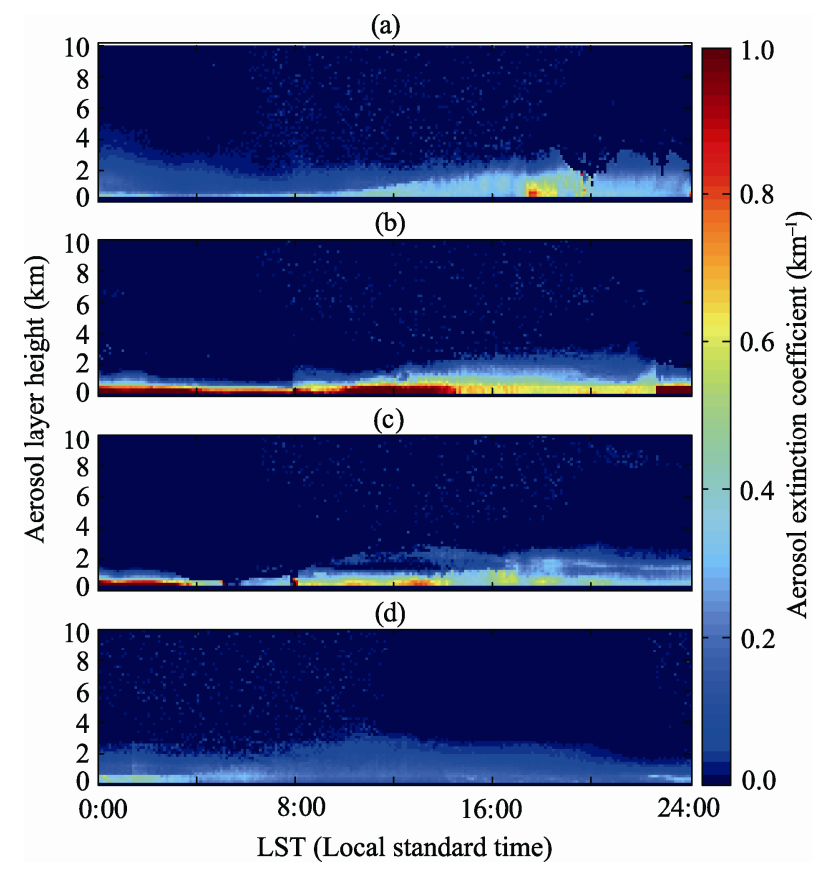

Fig. 4 The vertical distribution of aerosols on four consecutive days, from May 1 to May 4, 2008; (a) to (d) represent May 1, May 2, May 3, and May 4, 2008, respectively.

\subsection{Aerosol distribution in a sandstorm process}

Figure 5 shows the vertical profile of the AEC for the full day from May 1 to May 4. Data obtained on a sunny day (May 4) was used to compare the aerosol distributions. The AEC for the four days was different from one another. During the sandstorm, the AEC increased in a level of less than $5 \mathrm{~km}$. According to the distribution pattern, four stages were observed. In particular, in the first stage of the sandstorm (in the afternoon and evening of May 1), the AEC increased, and the maximum ALH was $3 \mathrm{~km}$. The extinction profile showed a small height gradient between 0.5 and 2 $\mathrm{km}$, indicating thorough mixing as a result of the ascending air current. During the second stage of the sandstorm (from the evening of May 1 to the morning of May 3), the extinction profile showed an exponential decrease in height, and the AEC reached its maximum below the height of $2 \mathrm{~km}$ near the ground surface, indicating unstable atmospheric conditions. During the third stage of the sandstorm (in the afternoon of May 3), the extinction profile displayed a small height gradient at an elevation of 0.5 to $1.5 \mathrm{~km}$. A value of $0.5 \mathrm{~km}^{-1}$ was attained, which was indicative of thorough mixing during the aerosol deposition stage. Additionally, another small height gradient was observed at an altitude from 1.5 to $3 \mathrm{~km}$, and the AEC 
(1)
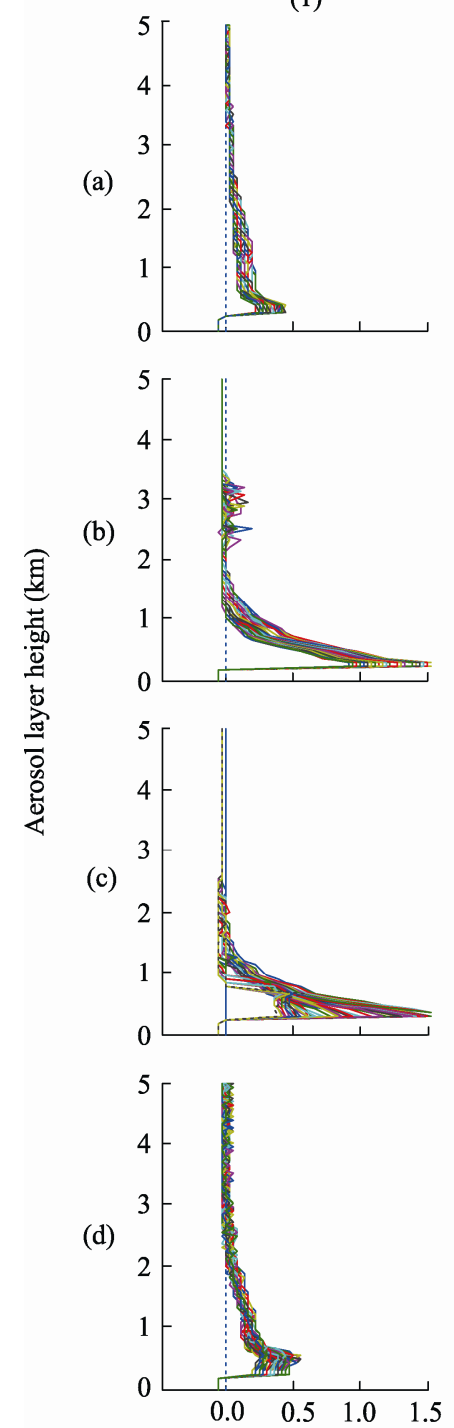

(2)
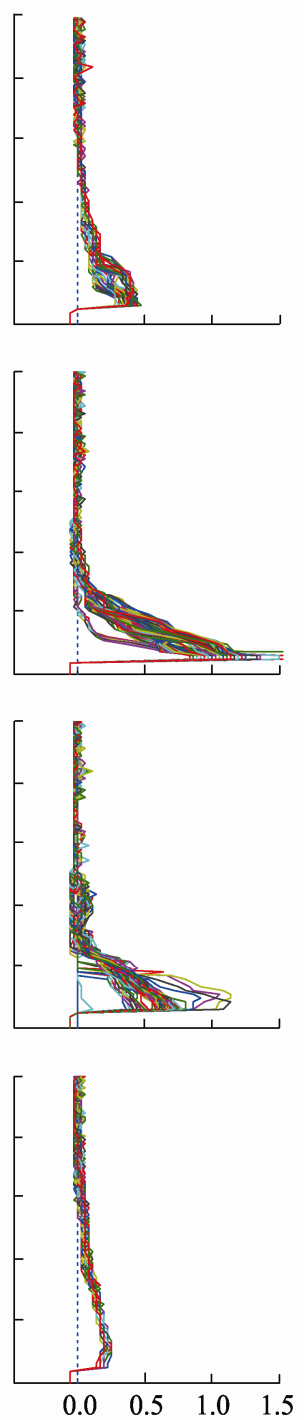

(3)
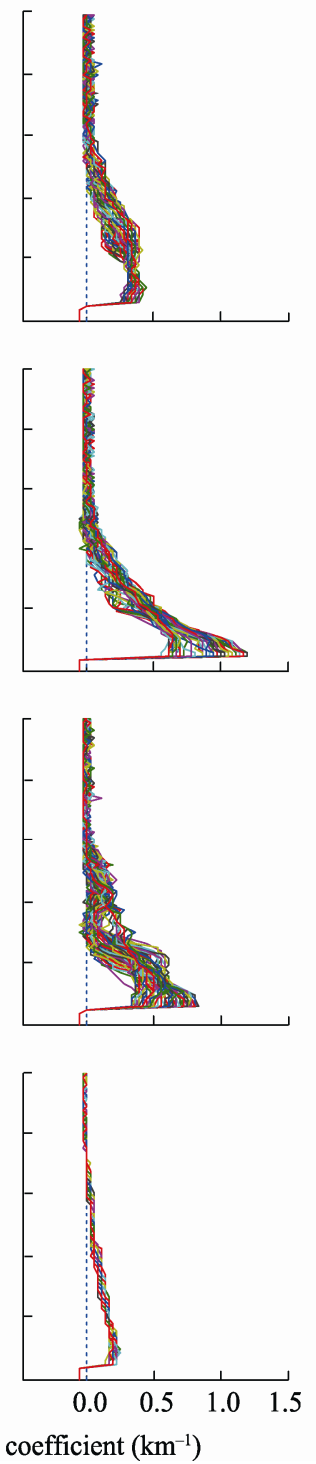

(4)
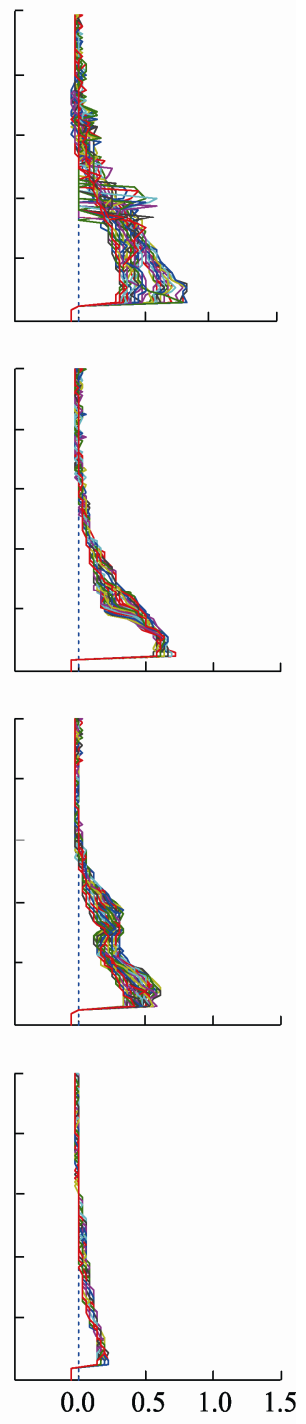

Fig. 5 The pattern of the vertical profiles of aerosol extinction coefficient (AEC) at SACOL, Gansu province, China; (a) to (d) illustrate date May 1, May 2, May 3, and May 4, 2008, respectively; (1) to (4) represent time from 0:00 to 6:00, 6:00 to 12:00, 12:00 to 18:00, and 18:00 to 24:00, respectively; the dash lines represent the air molecule EC.

was approximately $0.2 \mathrm{~km}^{-1}$. The pattern of the profile was the same as that of the first stage. During the fourth stage, the extinction profile showed a paracurve gradient in height, and the maximum value was observed at $0.3-0.5 \mathrm{~km}$. The AEC was less than $0.5 \mathrm{~km}^{-1}$, which was the same as the pattern during the night and morning of May 1 and is indicative of a normal aerosol distribution on a sunny day. These four stages and three structures suggest two possibilities: strong turbulence may have lifted the aerosols upward from low levels near the ground surface during the sandstorm or convective lifting and the transport of aerosols from distant sources may have occurred in response to horizontal and upper air movement. These two possibilities must be tested in accordance with the atmospheric conditions. Based on the AEC from 0.36 to $1.08 \mathrm{~km}^{-1}$ at Shapoto, a sand desert region in the southeastern edge of Tengger Desert, Meloni et al. (2005) suggested that there were three typical patterns of vertical dust profiles: (I) a stably stratified dust layer (with an extinction profile showing an exponential decrease in height), (II) a well-mixed dust layer (with an extinction profile showing a small height gradient), and (III) an elevated dust layer (with an ex- 
tinction profile showing a positive gradient around the bottom of the layer). The three distribution patterns occurred at the SACOL station even though the SACOL is far from sand sources. It can be inferred that sand-dust aerosol distributions exhibit three patterns, which may be affected by atmospheric conditions.

\subsection{Aerosol distribution in the spring}

Individual analyses indicated that the vertical distribution of sand-dust aerosols has diurnal variations. Similarly, the average AEC in the spring presents diurnal variations. Figure 6 shows the vertical distribution of the AEC over SACOL in the spring of 2008 (the average value was calculated from data obtained in April and May). The AEC showed clear diurnal variations, and a single peak distribution. The peak EC occurred from 12:00 to 14:00 LST, and the largest variation in the AEC was $0.46 \mathrm{~km}^{-1}$. The ALH in the lower layer has a single peak from 10:00 to 15:00, and the height was between 2 and $3 \mathrm{~km}$. The diurnal variability of the AEC and ALH for the spring was the same as that for April but different from that for May (figures not shown). The different conditions in May and April are due to the occurrence of two strong sandstorm processes in May and the absence of sandstorms in April. However, the AEC was still high in April and for spring, probably due to dust tornadoes and urban aerosols. Compared with sandstorm-free days, the ALH during sandstorm days (especially during aerosol lifting stage and transportation stage) is more complex and disordered. Because there are more sandstorm-free days in spring just as in April, the average AEC and ALH for spring are the same as for April. Analysis shows that the diurnal ALH in April is in agreement with the BLH, and it is inferred that BLH movement will affect the ALH.

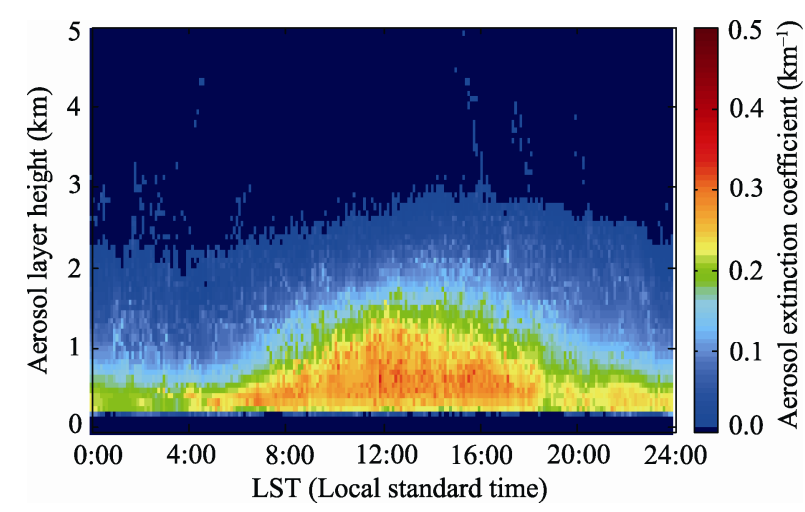

Fig. 6 The AEC distribution over SACOL during the spring of 2008
Figure 7 shows the average AEC profiles at night and during the daytime in the process of a sandstorm. The AEC profiles during dust storms also showed diurnal variability, but there are different patterns manifest in three stages, i.e. all sandstorm events in the spring can be divided into three parts or stages according to notable changes of aerosol profiles. The three stages are: the first stage (a small height gradient, well-mixed during ascent), the middle stage (an exponential decrease in height during transport), and the last stage (a small height gradient during deposition). These AEC profiles are also very similar to the individual cases shown in Fig. 5, in particular showing a small height gradient in the first stage (a), an exponential decrease in height in the second stage (b), and a small height gradient in the third stage (c). The ALH was high during daytime and low at night in the transportation stage (b) and deposition stage (c). The ALH was $2.5 \mathrm{~km}$ and $1.3 \mathrm{~km}$ respectively for day and night during the transportation stage, and $3.0 \mathrm{~km}$ and $1.8 \mathrm{~km}$ in the deposition stage. Under most conditions, the ALH was also higher in the afternoon and lower in the evening and deep night. In contrast, during the first sandstorm stage, the ALH is very similar with each other due to mixing by dynamical processes. AEC and ALH diurnal variations will be affected by atmospheric stability. The aerosol profiles can be used to parameterize climate and aerosol models, to determine the climatic and optical effects of aerosols, and to correct atmospheric profile retrieval from remote sensing.

\subsection{Relationship between ALH and BLH}

The AEC profiles of the above cases and average values in the spring show that the ALH had obvious diurnal variations. Figure 8 illustrates the temporal patterns of the ALH and BLH from May 1 to May 4 (from 0 to $96 \mathrm{~h}$ ), 2008 to understand the relationship between ALH and BLH. It is found that the ALH and BLH had inverse variability before $36 \mathrm{~h}$, while the trends coincide after $36 \mathrm{~h}$. Also, ALH was higher than BLH from 12 to $24 \mathrm{~h}, 36$ to $48 \mathrm{~h}, 84$ to $96 \mathrm{~h}$, respectively, demonstrating that the ALH was not affected by the BLH before $36 \mathrm{~h}$, especially from 12 to $24 \mathrm{~h}$. This represents the strong sandstorm stage from May 1 to May 2, which is in agreement with the atmospheric conditions presented by Figs. 2 and 3. The sand-dust 

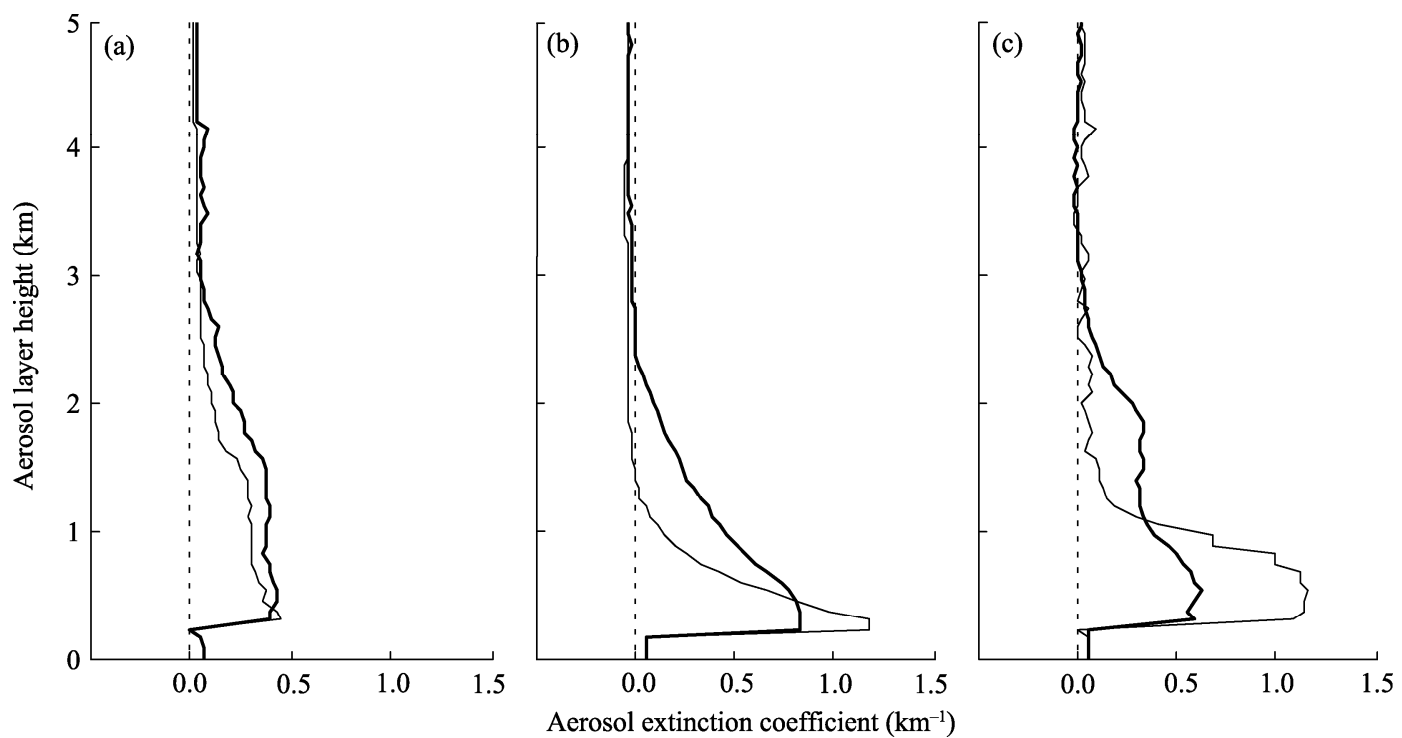

Fig. 7 Aerosol vertical distributions at night (thin curve) and during the day (thick curve) in the spring from 2007 and 2008; (a) to (c) represent the first stage, the middle stage, and the last stage in the process of a dust storm, respectively.

aerosols were transported from outer regions through the free atmosphere and boundary layer, therefore the ALH was mainly being affected by atmospheric circulation during the main sandstorm event. After $36 \mathrm{~h}$, the weather system had become weak and the ALH was low at night and high in the afternoon. The average ALH in spring was also high in the afternoon and low at night, which is in agreement with the BLH pattern. The reason is that the ALH was mainly affected by BLH movement. The relationship between the ALH and BLH can explain the AEC profiles shown in Figs. 5-7. Figure 8 also shows that the ALH was affected not only by atmospheric circulation, but also by BLH movement.

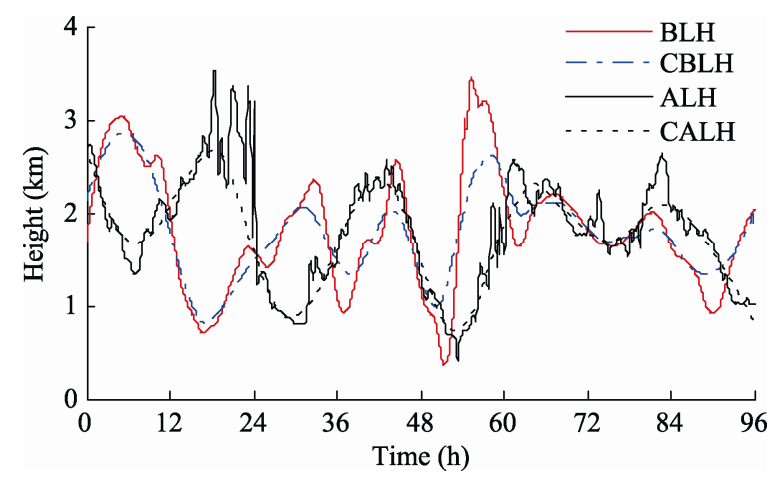

Fig. 8 Temporal patterns of ALH and BLH over SACOL from May 1 to May 4, 2008. CBLH and CALH are the smoothed lines of $\mathrm{BLH}$ and $\mathrm{ALH}$, respectively.

\section{Conclusions}

The results indicate that aerosol distribution was not only affected by atmospheric circulation, but also by boundary layer movement. Aerosol distribution as a function of altitude showed a single peak under stable atmospheric conditions, and aerosol distribution in the mixed layer did not change significantly. The AEC in the presence of unstable stratification showed an exponential distribution. The aerosol distributions can be useful for parameterizing climate and aerosol models, determining the climatic and optical effects of aerosols, and correcting atmospheric profiles from remote sensing and radiance transfer models.

During the first sandstorm stage, the ALH was complex and disordered; however, the ALH in other conditions was affected by the diurnal variations of the ABL. After the first sandstorm stage the ABL and ALH showed a single peak distribution and were low in the morning and high in the afternoon. Altitudes for ALH during the deposition stage in 2008 were found to be $3.5 \mathrm{~km}$ and $1.8 \mathrm{~km}$ in the afternoon and at night, respectively. The maximum ALH appeared from 12:00 and 16:00 LST.

Two possible transportation paths were observed in the study region. In one path, sand-dust aerosols were transported from the Taklimakan Desert toward the east to the Badain Jaran and Tengger deserts by 
westerly winds and then toward the southeast to Jingtai and Lanzhou. In the other path, dust was possibly transported from the Taklimakan Desert toward the east to the Qaidam Basin and passed eastward through the Tibetan Plateau to Lanzhou and the SACOL. The second path needs further testing by comparing more observed events. A weak AI in the Tibetan Plateau shows that sand-dust aerosols can come from the Plateau and can be easily transported into the free atmosphere.

As the SACOL station lies near the Lanzhou urban

\section{References}

Anderson T L, Masonis S J, Covert D S, et al. 2003. Variability of aerosol optical properties derived from in situ aircraft measurements during ACE-Asia. Journal of Geophysical Research, 108(23): $8647-8666$

Arimoto R, Duce R A, Savoie D L, et al. 1996. Relationships among aerosol constituents from Asia and the North Pacific during PEM-West. Journal of Geophysical Research, 101(1): 2011-2023.

Campbell J R, Hlavka D L, Welton E J, et al. 2002. Full-time, eye-safe cloud and aerosol lidar observation at atmospheric radiation measurement program sites: instruments and data processing. Journal of Atmospheric and Oceanic Technology, 19: 431-442.

Claquin T, Schulz M, Balkanski Y J, et al. 1998. Uncertainties in assessing radiative forcing by mineral dust. Tellus (B), 50: 491-505.

Clarke A D, Shinozuka Y, Kapustin V N, et al. 2004. Size distribution and mixture of dust and black carbon aerosol in Asian outflow: physiochemistry and optical properties. Journal of Geophysical Research, 109(15): 9-29.

Derek E D, William C M. 2001. Aerosol light scattering measurements as a function of relative humidity: a comparison between measurements made at three different sites. Atmospheric Environment, 35: 5169-5176.

Fernald F G. 1984. Analysis of atmospheric lidar observations: some comments. Applied Optics, 23: 652-653.

Forster P, Ramaswamy V, Artaxo P, et al. 2007. Changes in atmospheric constituents and in radiative forcing. In: Climate Change 2007: The Physical Science Basis, Working Group I to the Fourth Assessment Report of the Intergovernmental Panel on Climate Change. United Kingdom and New York: Cambridge University Press, 129-234.

Gille G W, Emmons J C, Heald L, et al. 2003. Transport and chemical evolution over the Pacific (TRACE-P) aircraft mission: design, execution, and first results. Journal of Geophysical Research, 108: $1-19$.

Han Y, Dai X, Fang X, et al. 2008. Dust aerosols: a possible accelerant for an increasingly arid climate in North China. Journal of Arid Environments, 72: 1476-1489.

Han Y X, Fang X M, Song L C, et al. 2005. A study of atmospheric area and is affected by urban aerosols, the three patterns of aerosol distribution during sandstorms were affected by urban aerosol movement, especially in the low layer.

\section{Acknowledgments}

This research was funded by the National Natural Science Foundation of China (40805009) and the Priority Academic Program Development (PAPD) of Jiangsu Higher Education Institutions. Support was from SACOL stations (Semi-Arid Climate \& Environment Observatory of Lanzhou University). The authors would like to thank ZhongWei HUANG, JianRong BI and BeiDou ZHANG for their assistance in data processing.

circulation and dust storm causes of formation in the Tarim Basin: the restructured wind field by shapes of dune and observed prevailing wind. Chinese Journal of Atmospheric Sciences, 29(4): $627-635$.

He Q S, Mao J T, 2004. Micro-pulse lidar and its applications. Meteorological Science and Technology, 42(4): 219-224.

Huang J P, Lin B, Minnis P, et al. 2006a. Satellite-based assessment of possible dust aerosols semi-direct effect on cloud water path over East Asia. Geophysical Research Letters, 33, L19802, doi: 10.1029/2006L026561.

Huang J P, Minnis P, Lin B, et al. 2006b. Possible influences of Asian dust aerosols on cloud properties and radiative forcing observed from MODIS and CERES. Geophysical Research Letters, 33, L06824, doi: 10.1029/2005GL024724.

Huang J P, Huang Z W, Bi J R, et al. 2008a. Micro-pulse lidar measurements of aerosol vertical structure over the Loess Plateau. Atmospheric and Oceanic Science Letters, 1: 8-11.

Huang J P, Zhang W, Zuo J Q, et al. 2008b. An overview of the semi-arid climate and environment research observatory over the Loess Plateau. Advances in Atmospheric Sciences, 25(6): 906-921.

In H J, Park S U. 1999. A simulation of long-range transport of yellow sand observed in April 1998 in Korea. Atmospheric Environment, 36: 4173-4187.

Iwasaka Y, Shibata T, Nagatani T, et al. 2003. Large depolarization ratio of free tropospheric aerosols over Taklimakan Desert revealed by lidar measurements: possible diffusion and transport of dust particles. Journal of Geophysical Research, 108: 8652-8660.

Kim S W, Yoon S C, Jefferson A, et al. 2004. Observation of enhanced water vapor in Asian dust layer and its effect on atmospheric radiative heating rates. Geophysical Research Letters, 31: 18113-18117.

Kinne S, Schultz M, Textor C, et al. 2006. An aero cominitial assessment-optical properties in aerosol component modules of global models. Atmospherical Chemistry Physics, 6: 1815-1834.

Levin Z, Ganor E, Gladstein V. 1996. The effects of desert particles coated with sulfate on rain formation in the Eastern Mediterranean. Journal of Applied Meteorology, 35: 1511-1523. 
Levy R C, Remer L A, Dubovik O. 2007. Global aerosol optical properties and application to moderate resolution imaging spectroradiometer aerosol retrieval over land. Journal of Geophysical Research, 112, D13210, doi: 10.1029/2006JD007815.

Li C, Marufu L T, Dickerson R R, et al. 2005. In-situ measurements of trace gases and aerosol optical properties at a rural site in northern China during EAST-AIRE IOP 2005. Journal of Geophysical Research, 112, D22S04, doi: 10.1029/2006JD007592.

Li Z, Chen H, Cribb M, et al. 2007a. Preface to special section: overview of the East Asain Study of Tropospheric Aerosols: an International Regional Experiment (EAST-AIRE). Journal of Geophysical Research, 112, D22S00, doi: 10.1029/2007JD008853.

Li Z, Xia X, Cribb M, et al. 2007b. Aerosol optical properties and their radiative effects in northern China. Journal of Geophysical Research, 112, D22S01, doi: 10.1029/2006JD007382.

Liao H, Seinfeild J H. 1998. Radiative forcing by mineral dust aerosols: sensitivity to key variables. Journal of Geophysical Research, 103(24): 31637-31645.

Liu J F, Mauzerall D L. 2007. Potential influence of inter-continental transport of sulfate aerosols on air quality. Environment Research Letters, 2: 045029-045036.

Liu Z, Liu D, Huang J, et al. 2008. Airborne dust distributions over the Tibetan Plateau and surrounding areas derived from the first year of CALIPSO lidar observations. Atmospheric Chemistry and Physics, 8: 5045-5060.

Meloni D, Sarra A D, Iotio T D, et al. 2005. Influence of the vertical profile of Saharan dust on the visible direct radiative forcing. Journal of Quantitative Spectroscopy and Radiative Transfer, 93: 397-413.

Nakajima T, Sekiguchi M, Takemura T, et al. 2003. Significance of direct and indirect radiative forcing of aerosols in the East China Sea region. Journal of Geophysical Research, 108: 8658-8674.

Niranjan K, Madhavan B L, Sreekanth V. 2007. Micro pulse lidar observation of high altitude aerosol layers at Visakhapatnam located on the east coast of India. Geophysical Research Letters, 34, L03815, doi: 10.1029/2006GL028199.

Pace G, Sarra A, Meloni D, et al. 2006. Aerosol optical properties at Lampedusa (Central Mediterranean). Influence of transport and identification of different aerosol types. Atmospheric Chemistry and Physics, 6: 697-713.
Shine K P, Forster P M. 1999. The effect of human activity on radiative forcing of climate change: a review of recent developments. Global Planetary Change, 20: 205-225.

Sokolik I N, Toon O B. 1996. Direct radiative forcing by airborne mineral aerosols. Journal of Aerosol Science, 27: 11-12.

Takemura T, Uno I, Nakajima T, et al. 2002. Modeling study of long-range transport of Asian dust and anthropogenic aerosols from East Asia. Geophysical Research Letters, 29(24): 111-114.

Torres O, Bhartia P K, Sinyuk A, et al. 2005. Total ozone mapping spectrometer measurements of aerosol absorption from space: Comparison to SAFARI 2000 ground-based observations. Journal of Geophysical Research, 110(10): 18-30.

Uematsu M, Yoshikawa A, Muraki H, et al. 2002. Transport of mineral and anthropogenic aerosols during a Kosa event over East Asia. Journal of Geophysical Research, 107(7): 40-59.

Won J G, Yoon S C, Kim S W, et al. 2004. Estimation of direct radiative forcing of Asian dust aerosols with sun/sky radiometer and lidar measurements at Gosan, Korea. Journal of the Royal Meteorological Society Japan, 82: 115-130.

Yogesh K, Ghosh A B, Sharma M C, et al. 2000. Studies on aerosol optical depth in biomass burning areas using satellite and ground-based observations. Infrared Physics \& Technology, 41: 21-28.

Zhang J, Zhang Q. 2008. Aerosol impact and correction on temperature profile retrieval from MODIS. Geophysical Research Letters, 35, L13818, doi: 10.1029/2008GL034419.

Zhang Q, Wang S, Li Y. 2005. The depth of atmospheric boundary layer in arid region of northwest China. Acta Meteorologica Sinica, 19(5): 12-22.

Zhang Q, Wang S. 2009. A study on atmospheric boundary layer structure on a clear day of the arid region in northwest China. Acta Meteorologica Sinica, 23(3): 327-337.

Zhou X J, Xu X D, Yan P, et al. 2002. Dynamic characteristics of spring sand storms in 2000. Science in China: Series D, 45(10): 921-930.

Zhu A, Ramanathan V, Li F, et al. 2007. Dust plumes over the Pacific, Indian, and Atlantic oceans: climatology and radiative impact. Journal of Geophysical Research, 112, D16208, doi: 10.1029/ 2007JD008427. 